\title{
Recurrent femoral shaft fractures in a child with gnathodiaphyseal dysplasia: a case report
}

\author{
Takuma Kuroda ${ }^{1,2,3}$, Ichiro Okano ${ }^{2 *}$ (D) Takatoshi Sawada², Satoshi Okamoto ${ }^{2,3}$, Yuki Midorikawa ${ }^{2}$, Tetsuya Tachibana ${ }^{2}$, \\ Toshio Yagi ${ }^{2,3}$ and Katsunori Inagaki ${ }^{3}$
}

\begin{abstract}
Background: Gnathodiaphyseal dysplasia (GDD) is an extremely rare autosomal dominant disease characterized by cemento-osseous lesions in the jawbones, bone fragility, and diaphyseal sclerosis of the tubular bones. Patients with GDD are prone to sustain fractures by minor accidents. Although over 80 cases have been reported, detailed information about the orthopedic treatment of the fractures is limited.

Case presentation: A 9-year-old Japanese girl with a known history of GDD presented with pain and deformity in the left thigh after a minor fall. She had a displaced transverse fracture in the mid-shaft of the left femur and underwent a closed reduction and external fixation. In the 25th week after the initial surgery, she had another fracture in the left femur at one of the half-pin insertion sites. She underwent an external fixation again. After this operation, the patient sustained another refracture at the same fracture site and one supracondylar fracture at the distant site of the femur. The supracondylar fracture occurred without any triggering activity before beginning a weight-bearing exercise. The supracondylar fracture was successfully treated conservatively, but she sustained two more diaphyseal fractures at half-pin insertion sites one after another. She eventually underwent a revision surgery with a flexible intramedullary nail. At 3 months postoperatively, the fracture was healed and the patient maintained her ambulatory status without further refracture.
\end{abstract}

Conclusions: Patients with GDD might have narrower safety ranges of biomechanical and physiological drawbacks, which are considered to be acceptable in ordinary cases. The choice of treatment should be aimed at minimizing these negative effects. We recommend intramedullary devise as the first-choice implant for the treatment of isolated femoral shaft fracture in GDD patients in this age group.

Keywords: Gnathodiaphyseal dysplasia, Femoral shaft fractures, Recurrent fracture, External fixation, Intramedullary devise

\section{Background}

Gnathodiaphyseal dysplasia (GDD) is one of the extremely rare autosomal dominant diseases characterized by cemento-osseous lesions of the jawbones, bone fragility, and diaphyseal sclerosis of tubular bones [1]. The patients with GDD are prone to sustain fractures by minor accidents. To date, reports of approximately 80 affected individuals are available, and most of them have

\footnotetext{
* Correspondence: Ichiro.okano.e31@gmail.com; Okanol@hss.edu

${ }^{2}$ Department of Orthopedic Surgery, Ohta-Nisihinouchi hospital, 2-5-20

Nishinouchi, Koriyama, Fukushima 963-8558, Japan

Full list of author information is available at the end of the article
}

suffered fractures $[1,2]$. Although the underlying mechanism of bone fragility has not been completely elucidated, recent investigations demonstrated that mutations in the ANO5 gene were associated with the pathogenesis of GDD [1]. There are several reports that discuss the treatment of facial bone lesions [3, 4]. However, detailed information about the orthopedic treatment of the fractures is limited. In this report, we present a case of recurrent femoral shaft fractures in a 9-year-old female patient with GDD after surgical treatment and address the challenges in fracture management in this rare and difficult condition.

(c) The Author(s). 2019 Open Access This article is distributed under the terms of the Creative Commons Attribution 4.0 International License (http://creativecommons.org/licenses/by/4.0/), which permits unrestricted use, distribution, and reproduction in any medium, provided you give appropriate credit to the original author(s) and the source, provide a link to the Creative Commons license, and indicate if changes were made. The Creative Commons Public Domain Dedication waiver (http://creativecommons.org/publicdomain/zero/1.0/) applies to the data made available in this article, unless otherwise stated. 


\section{Case presentation}

A 9-year-old Japanese girl with a known history of nonhereditary GDD presented with pain and deformity in the left thigh after a minor fall. The GDD was diagnosed by the facial bone developmental dysplasia and genetic examination when she was 3 years old. She had a history of multiple fractures of various sites, such as bilateral tibia, fibula, thoracic vertebrae, cervical vertebrae, and coccyx. All previous fractures had been successfully treated conservatively without complications. Her bone mineral density (BMD) measured using dual-energy X-ray absorptiometry at the previous hospital 2 years ago was lower than the age-adjusted average; her spine BMD was $0.493 \mathrm{~g} / \mathrm{cm}^{2}$ and T-score was -5.9.

At the initial radiologic examination, a displaced transverse fracture (32-D/4.1 in AO Pediatric Comprehensive Classification of Long Bone Fractures (AO-PCCF) [5]) in the mid-shaft of left femur was observed (Fig. 1). Repositioning of the fracture fragments was not successful using skin traction with external hanging weights. Thus, the patient underwent a closed reduction and external fixation by using a unilateral fixator system (Hoffmann $\mathrm{II}^{\oplus}$, Stryker Corporation, Kalamazoo, MI) with 5-mm non-hydroxylapatite-coated half pins under general anesthesia 6 days after the injury (Fig. 2). The radiograph obtained at the 12-week follow-up showed a solid bony union at the fracture site, and the fixators were removed (Fig. 3). The patient was allowed to initiate and gradually advance weight bearing.

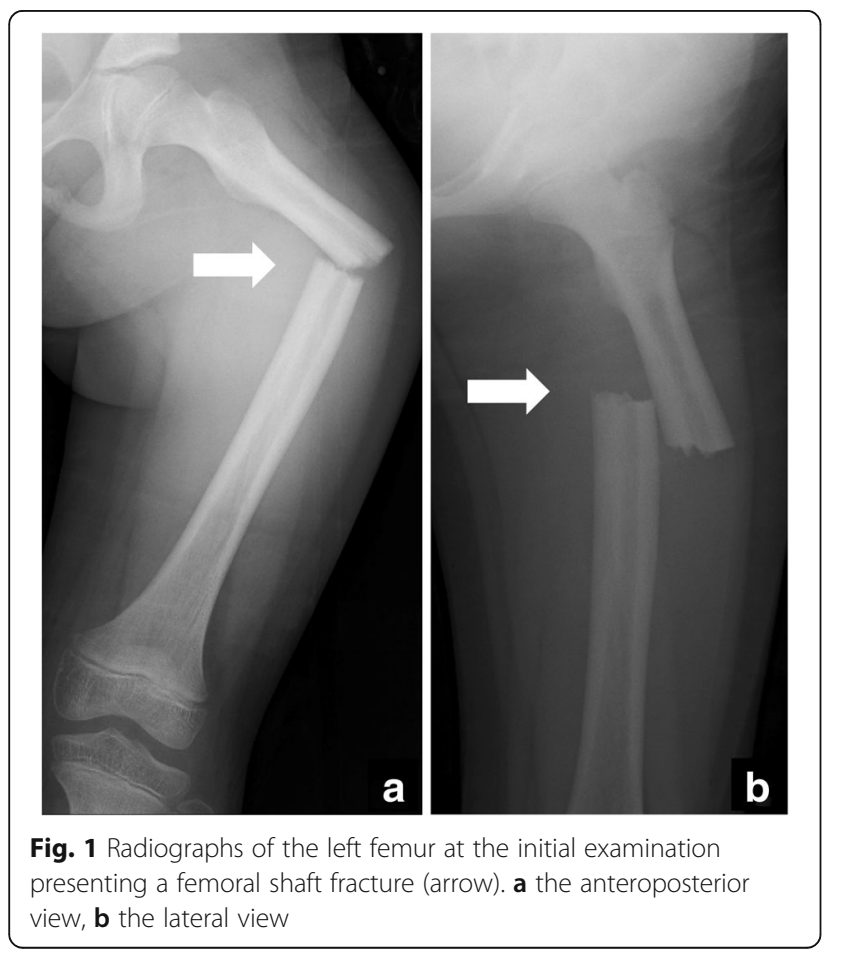

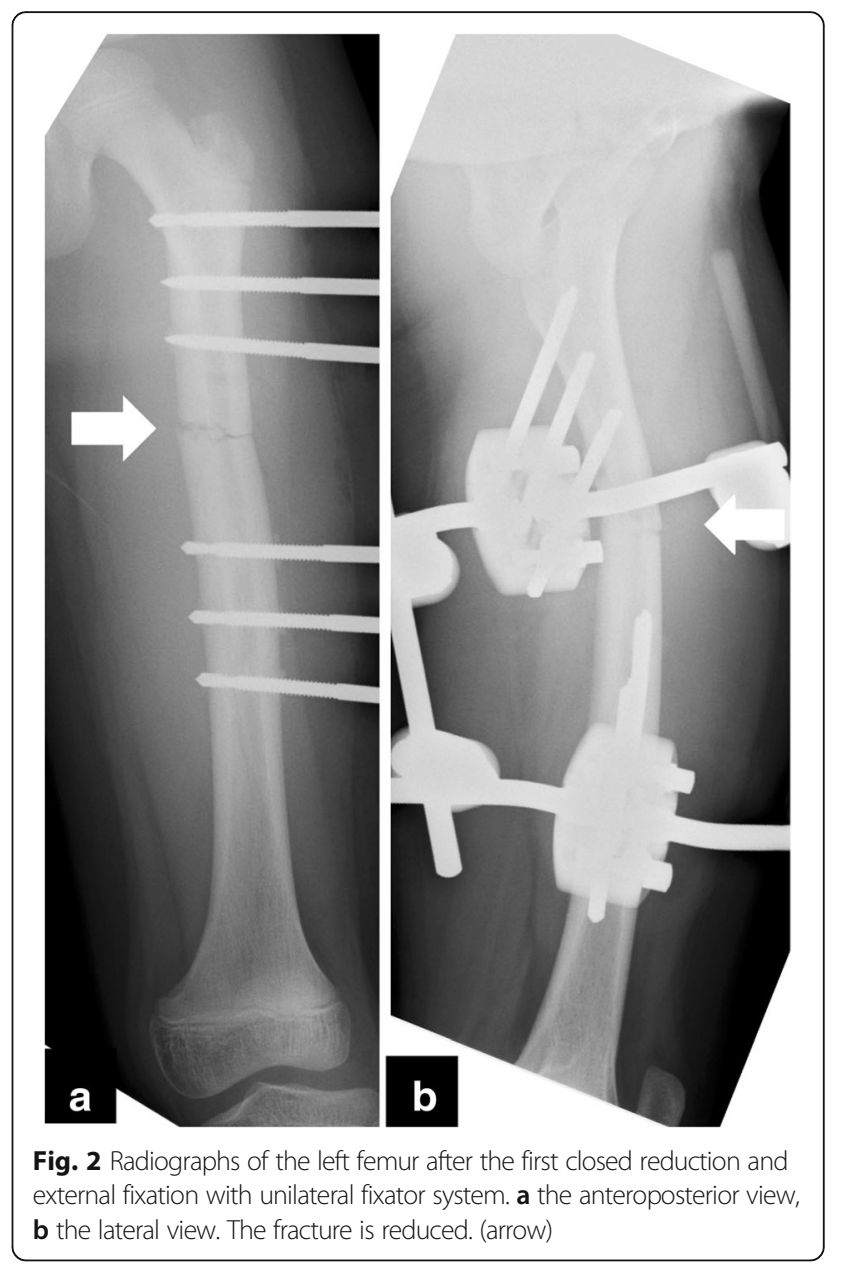

At 25 weeks after the initial surgery, she suddenly felt severe pain in her left thigh while she was walking and was unable to walk further. Radiological examinations revealed another fracture in the left femur (32-D/4.1 in AO-PCCF) at one of the half-pin insertion sites (Fig. 4). She underwent an external fixation again. After this operation, the patient sustained a refracture (32-D/4.1 in AO-PCCF) at the same fracture site, followed by a supracondylar fracture (33-M/3.1 in AO-PCCF) at a distant site of the femur (Fig. 5) and two consecutive fractures at the half-pin insertion sites (Fig. 6). The supracondylar fracture occurred without any triggering activity before beginning weight-bearing exercise. The supracondylar fracture was successfully treated conservatively, but she sustained two more consecutive diaphyseal fractures (32-D/4.1 and 32-D/4.1 in AO-PCCF) at the half-pin insertion sites (Fig. 6). She eventually underwent a revision surgery for the diaphyseal fractures with an Ender nail (Ender nail ${ }^{\circ}$, MIZUHO Co., Ltd., Tokyo, Japan). Open reduction was not easily achieved owing to the fracture deformity and growing callus. Only one nail could be passed through it because the medullary canal was significantly narrowed 


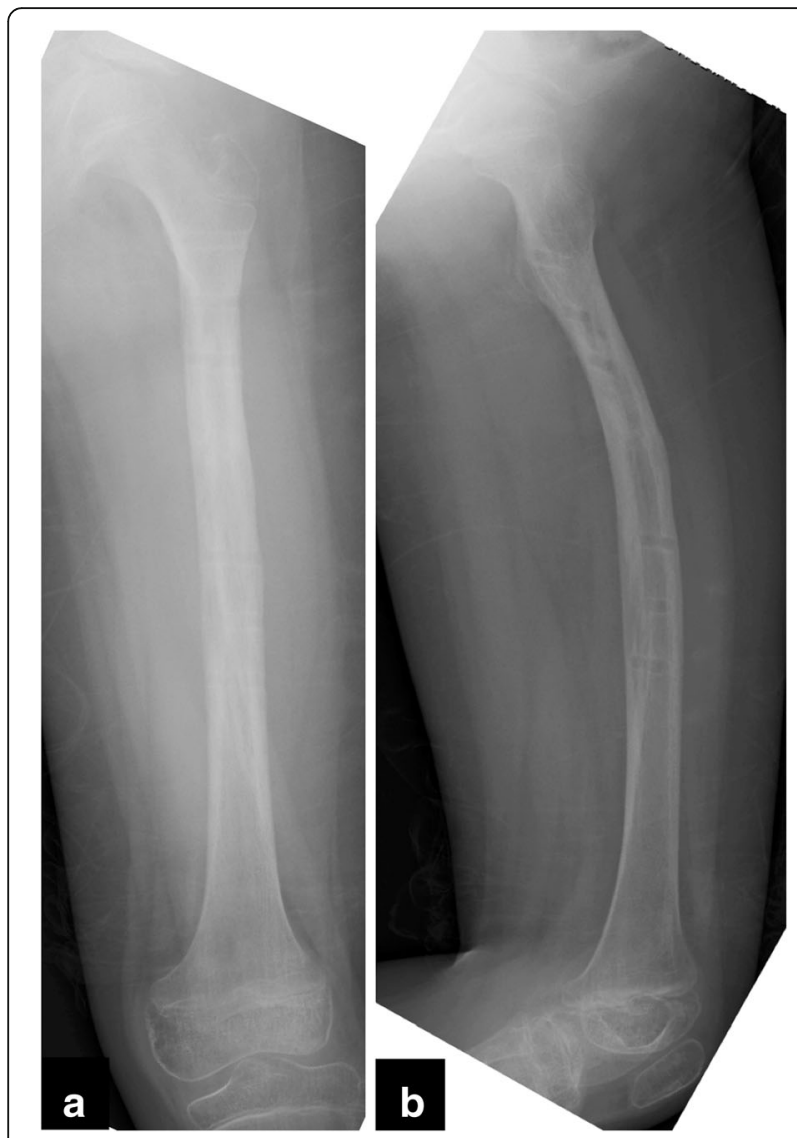

Fig. 3 Radiographs of the left femur at the 12-week follow-up after the first operation. $\mathbf{a}$ the anteroposterior view, $\mathbf{b}$ the lateral view

due to diaphyseal sclerosis associated with GDD (Fig. 7). After this operation, the patient started early functional rehabilitation and was allowed to progress gradually to partial weight bearing following pain relief. The radiographs at 5-month follow-up showed a solid bony union at all the fracture sites, and the Ender nail was removed (Fig. 8). Three months after the implant removal, the patient maintained her ambulatory status without further refractures.

\section{Discussion and conclusion}

We reported a case of a 9-year-old GDD patient with multiple recurrent fractures. To the best of our knowledge, no reports have been found regarding the detailed management of fracture in patients with GDD.

This patient was initially treated using a unilateral external fixator. However, the patient sustained multiple refractures in the fracture site as well as the half-pin insertion sites. Currently, more proportion of pediatric femoral shaft fractures are being treated surgically [6]. Several surgical options, including flexible intramedullary (IM) nail, solid IM nail, plate, and external fixation are available. At the time of the fracture, we adopted external fixation as the first-choice of treatment for the

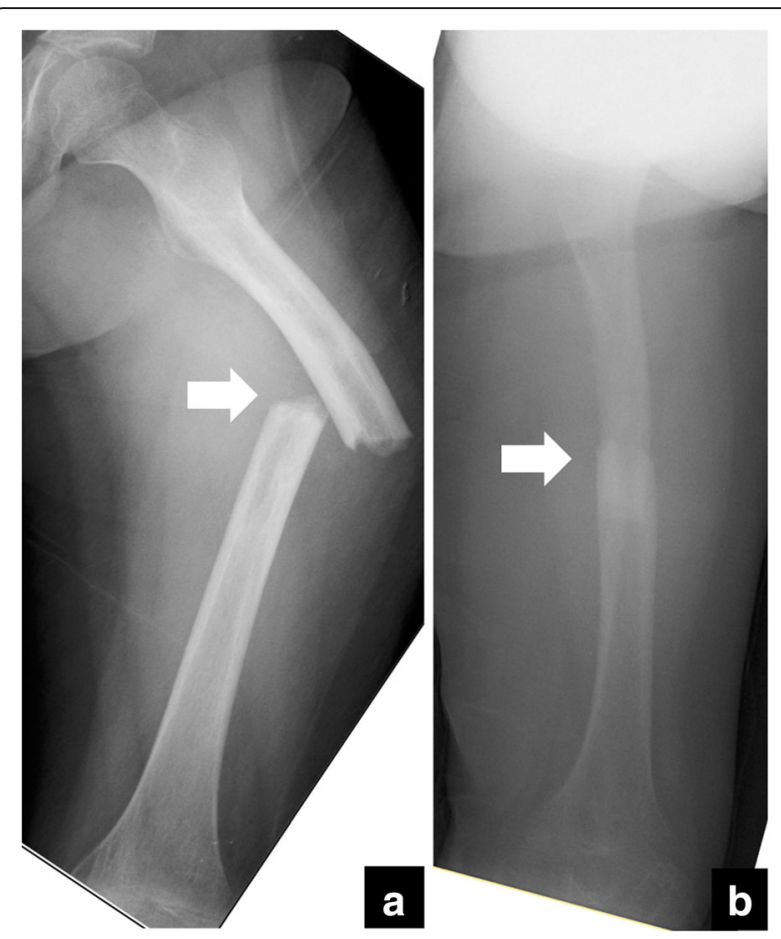

Fig. 4 Radiographs of the left femur at the first refracture at a pin-site. (arrow) (a) the anteroposterior view, (b) the lateral view

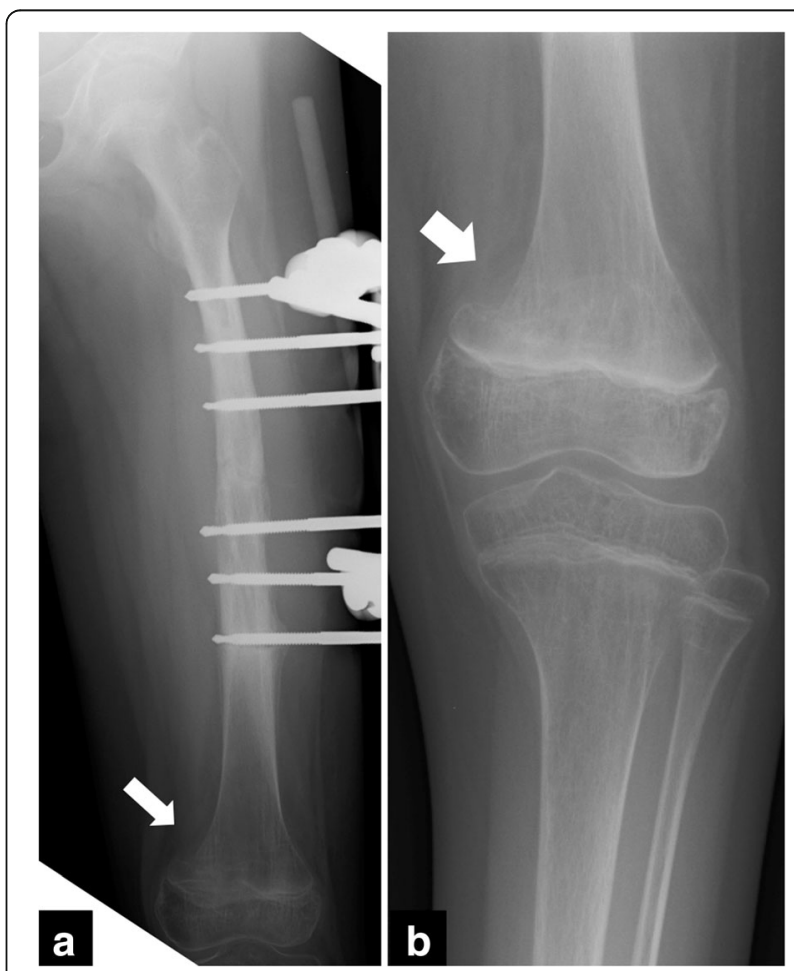

Fig. 5 a A radiograph of the left femur presenting a supracondylar fracture at the distant site of the right femur. (arrow) (b) An enlarged image of the supracondylar fracture site 


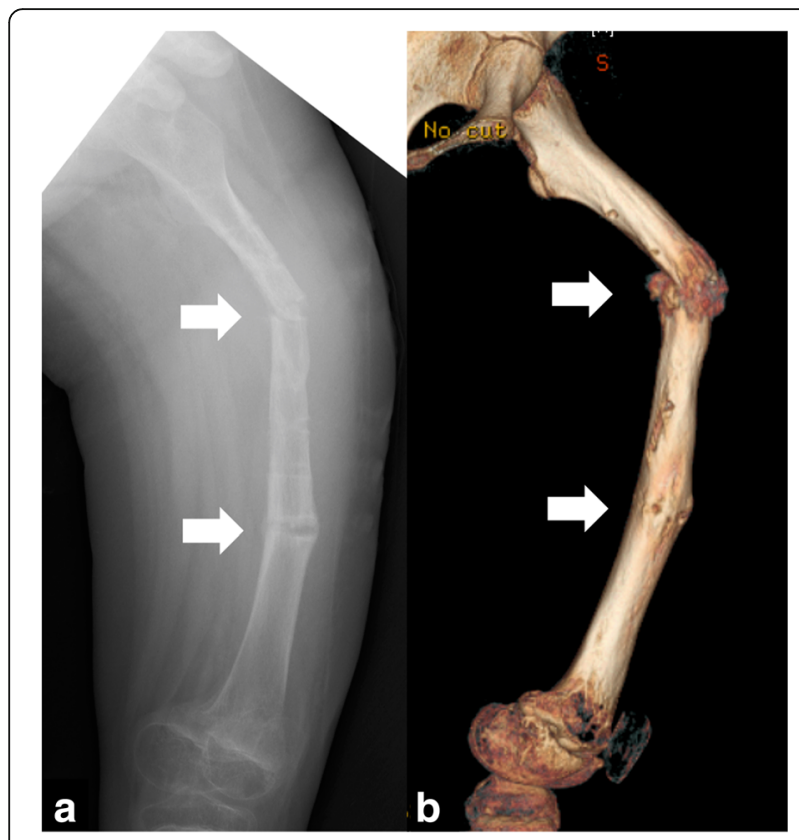

Fig. 6 a A radiograph of the left femur presenting the two fractures at half-pin insertion sites. (arrows) (b) The three-dimensional reconstruction of the left femur presenting the two fractures at halfpin insertion sites. (arrows)

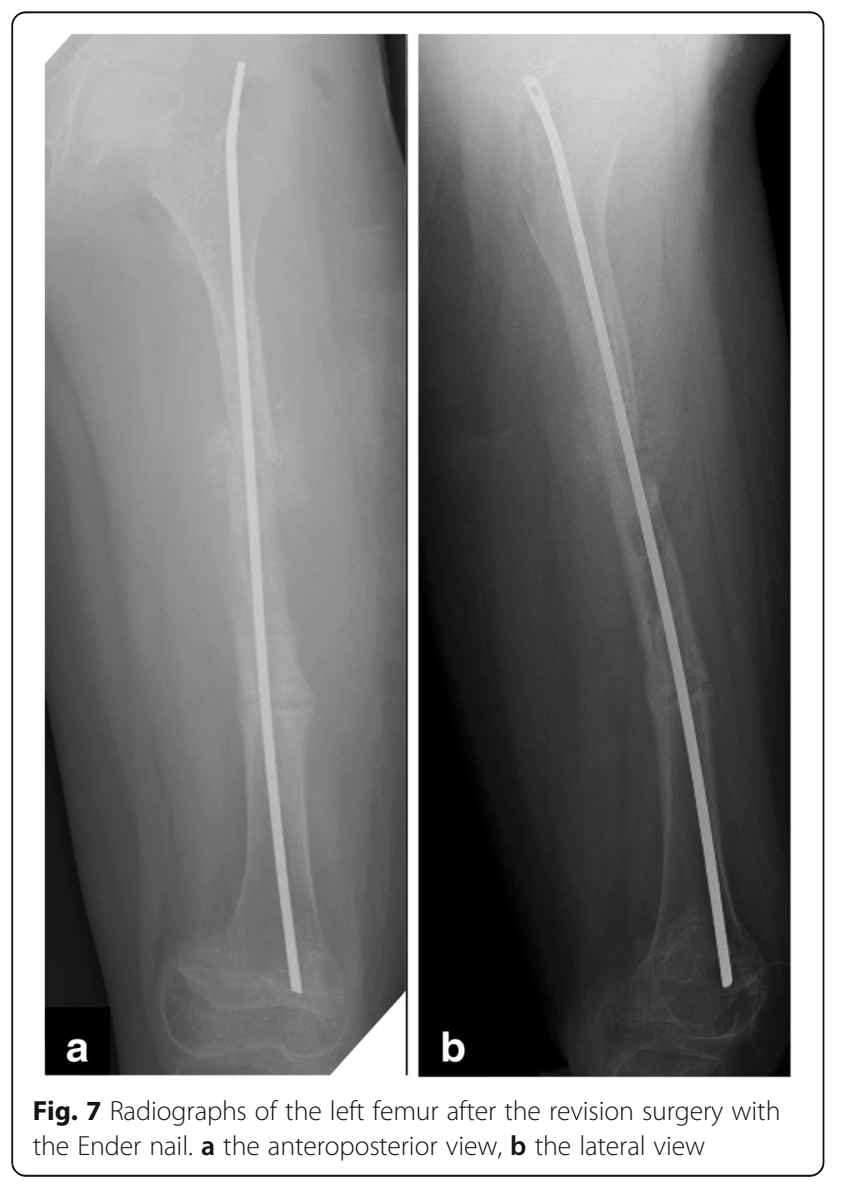

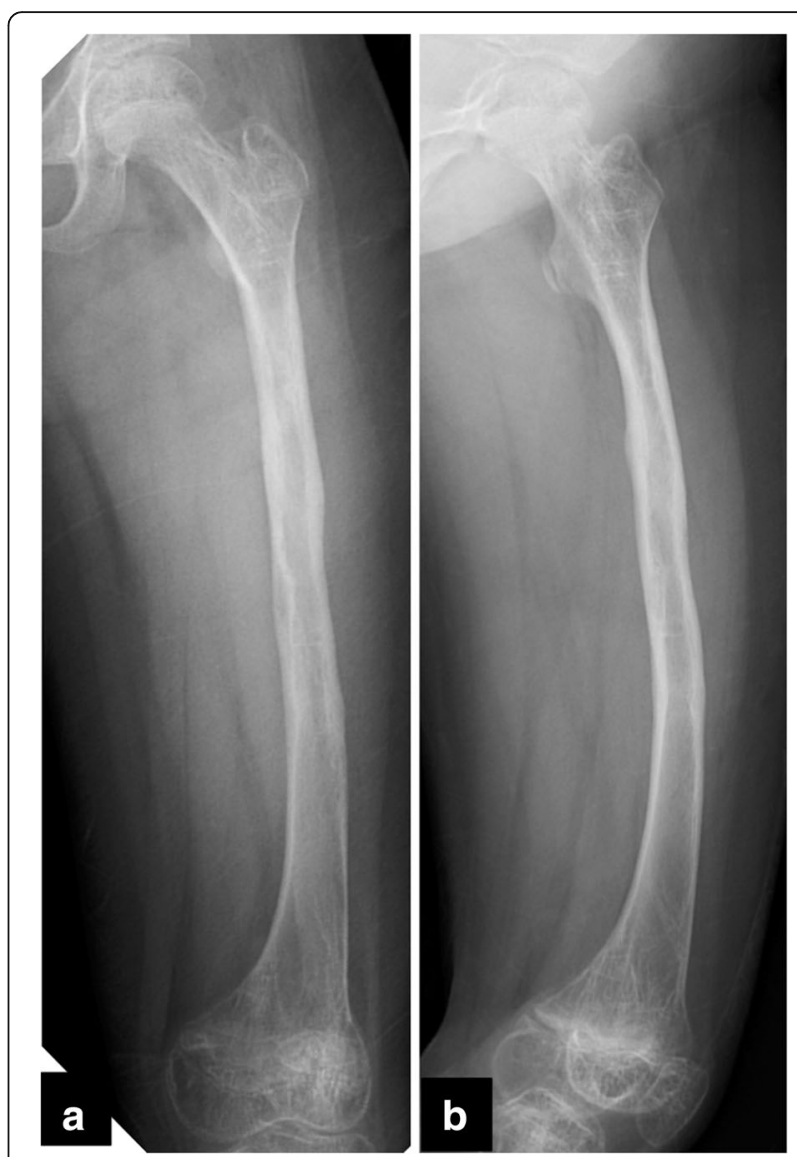

Fig. 8 Radiographs of the left femur after the revision surgery after the removal of Ender nail (5-month after the nail insertion) showing solid bony fusion of all fractures. $\mathbf{a}$ the anteroposterior view, $\mathbf{b}$ the lateral view

femoral shaft fracture in this age group. Previous studies showed that external fixation demonstrated results comparable with other fixation methods [7-9]. One of the major complications of external fixation is refracture after removal of the external fixator $[8,10-12]$. In previous reports, rates for refracture varied from 0 to $21.6 \%$ $[8,12,13]$. In their case series, Carmichael et al. [8] described that longer time in fixator was one of the risk factors for refracture. Although they did not determine the clear threshold, on comparison with their average fixator duration (11.7 weeks), prolonged fixator use was not relevant in our patient as a cause for the first refracture (12 weeks).

Previous reports also mentioned two major sites for refractures associated with external fixation: original fracture sites and pin insertion sites. Refractures at pin insertion sites were less frequent [8]. We utilized 5-mmdiameter half pins, as recommended, for pediatric femur fractures [14]; however, our patient had two refractures at the half-pin insertion sites. A biomechanical study showed that the presence of a $10 \%$ bicortical defect of bone circumference is sufficient to produce a reduction in peak 
torque [15]. Cortical defects created by a 5-mm-diameter half pin are likely to exceed a $10 \%$ bicortical defect in this age group [16]; however, these defects do not cause fractures in most cases. The GDD patients might not tolerate relatively small cortical bone defects associated with external fixator pin insertion.

In our patient, a refracture occurred 13 weeks after the removal of the external fixation. A previous study showed that refractures usually occurred in the earlier phase, an average of 8 days (1-21 days) after fixation removal [13]. In their animal study, Albert et al. demonstrated early screw hole filling of the woven bone and regained bone strength at 4 weeks after screw removal [17]. Although one might argue that directly applying the results of non-human studies to patients can be an issue, 13 weeks appeared enough to restore bone strength to the safety range. The altered healing process in GDD patients might sustain pin holes at high risk for refractures in a longer time period. Considering these disadvantages, external fixation was not considered suitable for the closed femoral shaft fracture in patients with GDD.

After five refractures, our patient was successfully treated using the Ender nail ${ }^{\circ}$, a flexible IM nail (FIN). FIN is widely accepted as a reliable and safe option for treatment of pediatric femoral shaft fractures [18-20]. A recent meta-analysis showed that FIN had a superior effectiveness for pediatric femoral fractures compared to external fixation in terms of time to union, limb-length discrepancy, refracture rate, infection rate, pain, bursitis rate, and patient satisfaction [18]. Some reports showed that FIN allowed the patients to perform earlier functional exercises after operation [21].

The IM device is also used as a first-line treatment of long-bone fractures among patients with osteogenesis imperfecta (OI), which is a systemic osseous fragility disease similar to GDD [22]. For patients with OI, more rigid IM devices are preferred to obtain stability. Two types of IM devices are used for fractures in OI: elongating and non-elongating rods. Elongating rods have self-extending designs to follow bone growth. Recently developed elongating rods, such as Sheffield and Fassier-Duval medullary rods, have become the standard treatment for patients with $\mathrm{OI}$ [22]. El-Adl et al. reported that elongating rods are better than non-elongating rods, such as Kirschner wires or rush pins, with regards to mobility status, longevity, and incidence of complications requiring reoperations [23]. In a previous report on a case of GDD, although the authors did not provide the description in detail, they mentioned that the patient was treated using elongating rods (the Fassier-Duval medullary rods) [24]. Given that recurrent refractures in our patient were a result of treatment with $\mathrm{EF}$, we recommend IM devices as the first choice for the treatment of femoral shaft fractures in GDD patients. In this case, we utilized the Ender nail as an IM device because elongating rods are not commercially available in our country and because other non-elongating IM devices such as rush pins and Kirchner wires only have limited size variations, which were not able to cover adequate lengths of the femur in our patient. It remains unclear whether fixation with a single Ender nail provides enough stability for patients with GDD. Considering the favorable results in OI, rigid and elongating rods may be a better option than non-elongating IM devices.

The non-ambulatory state is a known risk factor for secondary osteoporosis [25]. An increased risk of clinical fractures was observed among the non-ambulatory pediatric patients with chronic neuromuscular diseases $[25,26]$. In our patient, a long period of postoperative immobilization and non-weight-bearing might have caused secondary osteoporosis, which led to a supracondylar femoral fracture after the 2nd refracture. Fragility fractures associated with immobilization and non-weight bearing after an isolated fracture in the normally ambulatory children have been rarely reported. Patients with GDD might be more sensitive to mechanical environmental change caused by nonweight bearing, which is not usually related to worse clinical outcomes. Given the higher incidence of refractures among GDD patients and the potential vulnerability to non-weight bearing, we believe the implants that allow early functional rehabilitation should be selected for the treatment of femoral fractures in GDD to prevent this vicious cycle of refractures.

To prevent recurrent fractures, pharmacological therapy for bone fragility may be considered. Among OI patients, bisphosphonate therapy is currently the most common medical treatment and has been reported to decrease the incidence of long-bone fractures [27]. On the other hand, little is known about medications for patients with GDD. Ghada et al. reported a case of GDD treated with a bisphosphonate [1]. They demonstrated that bisphosphonate therapy did improve BMD of the spine. However; no apparent benefit was observed in terms of the frequency or severity of fractures. We proposed bisphosphonate therapy for our patient but could not obtain the care-givers' consent. They were mainly concerned about the potential adverse effects, particularly bisphosphonate-related osteonecrosis of the jaw, as the patient had GDD-associated lesions in the jawbone, which had required multiple surgical interventions. Therefore, further studies are needed to clarify the role of pharmacological therapy for GDD patients.

In summary, we suggest that patients with GDD might have narrower safety ranges of biomechanical (cortical defects by pin holes) and physiological (weight-bearing status) drawbacks, which are considered acceptable in ordinary cases. The choice of treatment should be aimed to minimize these negative effects, thus, within the available options, we recommend IM devise as the first-choice implant for isolated femoral shaft fracture in GDD patients in this age group. 


\section{Abbreviations}

AO-PCCF: AO Pediatric Comprehensive Classification of Long Bone FracturesOlosteogenesis imperfecta; BMD: bone mineral density; FIN: flexible intramedullary nail; GDD: Gnathodiaphyseal dysplasia; IM: intramedullary

\section{Acknowledgements}

The authors thank the patient's family for participating in our study. We thank Dr. Makoto Hodohara (Department of Orthopedic Surgery, Tokyo metropolitan Hiroo Hospital, Tokyo, Japan) for the comments on the manuscript.

\section{Funding}

The authors received no financial support for the research, authorship, or publication of this article.

\section{Availability of data and materials}

Data that support the findings of this study are available from the corresponding author on reasonable request.

\section{Authors' contributions}

TK conceptualized, collected and interpreted the clinical data, and wrote the manuscript. $1 \mathrm{O}$ and TS revised the manuscript critically for important content. SO, YM, TT, and TY collected the clinical data and revised the manuscript critically for important content. KI revised the manuscript critically for important content. All authors read and approved the final manuscript.

\section{Ethics approval and consent to participate}

Written informed consent was obtained from the patient's parents. A statement of the ethics committee was not required for this anonymized case report in accordance with the legislation of the Institutional Review Committee of Ohta-Nishinouchi Hospital.

\section{Consent for publication}

Written informed consent was obtained from the patient's parents for the publication of this case report. A copy of the written consent is available for review by the Editor of this journal.

\section{Competing interests}

The authors declare that they have no competing interests.

\section{Publisher's Note}

Springer Nature remains neutral with regard to jurisdictional claims in published maps and institutional affiliations.

\section{Author details}

${ }^{1}$ Department of Orthopedic Surgery, Showa University Northern Yokohama Hospital, Chigasaki-chuo 35-1, Tsuzuki-ku, Yokohama-shi, Kanagawa 224-8503, Japan. ${ }^{2}$ Department of Orthopedic Surgery, Ohta-Nisihinouchi hospital, 2-5-20 Nishinouchi, Koriyama, Fukushima 963-8558, Japan. ${ }^{3}$ Department of Orthopedic Surgery, Showa University School of Medicine, 1-5-8 Hatanodai Shinagawa-ku, Tokyo 142-8555, Japan.

\section{Received: 26 December 2018 Accepted: 12 February 2019}

\section{Published online: 23 February 2019}

\section{References}

1. Otaify GA, Whyte MP, Gottesman GS, McAlister WH, Eric Gordon J, Hollander A, et al. Gnathodiaphyseal dysplasia: severe atypical presentation with novel heterozygous mutation of the anoctamin gene (ANO5). Bone. 2018;107: 161-71. https://doi.org/10.1016/j.bone.2017.11.012.

2. Ahluwalia J, Ly JQ, Norman E, Costello RF Jr, Beall DP. Gnathodiaphyseal dysplasia. Clin Imaging. 2007;31(1):67-9. https://doi.org/10.1016/j.clinimag. 2006.07.003.

3. Said MM, Otomaru T, Kanazaki A, Fujita H, Taniguchi H. Prosthodontic treatment of a patient with gnathodiaphyseal dysplasia: 30-year follow-up. Int J Prosthodont. 2018;31(2):138-41. https://doi.org/10.11607/ijp.5585.

4. Merlini A, Garibaldi J, Giorgis L, Balbi P. Gnathodiaphyseal dysplasia: surgical treatment and prosthetic rehabilitation of 2 members of the same family. J Oral Maxillofac Surg. 2016;74(12):2441-6. https://doi.org/ 10.1016/j.joms.2016.06.006.
5. AO Foundation. $\mathrm{AO}$ pediatric comprehensive classification of long bone fractures (PCCF). J Orthop Trauma. 2018;32(Suppl 1):S117-40. https://doi.org/ 10.1097/bot.0000000000001065.

6. Flynn CJ, Danjoux C, Wong J, Christakis M, Rubenstein J, Yee A, et al. Two cases of acrometastasis to the hands and review of the literature. Curr Oncol. 2008;15(5):51-8.

7. Kong H, Sabharwal S. External fixation for closed pediatric femoral shaft fractures: where are we now? Clin Orthop Relat Res. 2014;472(12):3814-22. https://doi.org/10.1007/s11999-014-3554-5.

8. Carmichael KD, Bynum J, Goucher N. Rates of refracture associated with external fixation in pediatric femur fractures. Am J Orthop (Belle Mead NJ). 2005;34(9):439-44 discussion 444

9. Andreacchio A, Marengo L, Canavese F, Pedretti L, Memeo A. Comparison between external fixation and elastic stable intramedullary nailing for the treatment of femoral shaft fractures in children younger than 8 years of age. J Pediatr Orthop B. 2016;25(5):471-7. https://doi.org/10.1097/BPB. 0000000000000342

10. Skaggs DL, Leet Al, Money MD, Shaw BA, Hale JM, Tolo VT. Secondary fractures associated with external fixation in pediatric femur fractures. J Pediatr Orthop. 1999;19(5):582-6.

11. Probe R, Lindsey RW, Hadley NA, Barnes DA. Refracture of adolescent femoral shaft fractures: a complication of external fixation. A report of two cases. J Pediatr Orthop. 1993;13(1):102-5.

12. Wani MM, Dar RA, Latoo IA, Malik T, Sultan A, Halwai MA. External fixation of pediatric femoral shaft fractures: a consecutive study based on 45 fractures. J Pediatr Orthop B. 2013;22(6):563-70. https://doi.org/10.1097/BPB ob013e32836421ce.

13. Kesemenli CC, Necmioglu S, Kayikci C. Treatment of refracture occurring after external fixation in paediatric femoral fractures. Acta Orthop Belg. 2004; 70(6):540-4.

14. Hedin $\mathrm{H}$, Larsson $\mathrm{S}$. Technique and considerations when using external fixation as a standard treatment of femoral fractures in children. Injury. 2004; 35(12):1255-63. https://doi.org/10.1016/j.injury.2003.07.006.

15. Ho KW, Gilbody J, Jameson T, Miles AW. The effect of $4 \mathrm{~mm}$ bicortical drill hole defect on bone strength in a pig femur model. Arch Orthop Trauma Surg. 2010;130(6):797-802. https://doi.org/10.1007/s00402-010-1093-4.

16. Ohba S. Anthropological study on the Japanese femur. (in Japanese). Archives of Department of Anatomy, Jikei University school of. Medicine. 1950:3:1-44.

17. Burstein AH, Currey J, Frankel VH, Heiple KG, Luseth P, Vessely JC. Bone strength: the effect of screw holes. JBJS. 1972;54(6):1143-56.

18. Zhang YT, Jin D, Niu J, Li ZJ, Fu S. Zou ZL. A meta-analysis of external fixation and flexible intramedullary nails for femoral fractures in children. Acta Orthop Belg. 2016;82(4):673-80.

19. Lohiya R, Bachhal V, Khan U, Kumar D, Vijayvargiya V, Sankhala SS, et al. Flexible intramedullary nailing in paediatric femoral fractures. A report of 73 cases. J Orthop Surg Res. 2011;6:64. https://doi.org/10.1186/1749-799x-6-64.

20. Baldwin K, Hsu JE, Wenger DR, Hosalkar HS. Treatment of femur fractures in school-aged children using elastic stable intramedullary nailing: a systematic review. J Pediatr Orthop B. 2011;20(5):303-8. https://doi.org/10.1097/BPB. Ob013e32834671d0

21. Bar-On E, Sagiv S, Porat S. External fixation or flexible intramedullary nailing for femoral shaft fractures in children. A prospective, randomised study. J Bone Joint Surg Br. 1997;79(6):975-8.

22. Esposito P, Plotkin $\mathrm{H}$. Surgical treatment of osteogenesis imperfecta: current concepts. Curr Opin Pediatr. 2008;20(1):52-7. https://doi.org/10.1097/MOP. ob013e3282f35f03.

23. El-Adl G, Khalii MA, Enan A, Mostafa MF, El-Lakkany MR. Telescoping versus non-telescoping rods in the treatment of osteogenesis imperfecta. Acta Orthop Belg. 2009;75(2):200-8.

24. Herman TE, Siegel MJ, Sargar K. Gnathodiaphyseal dysplasia. J Perinatol. 2014;34(5):412-4. https://doi.org/10.1038/jp.2013.178.

25. Munns CF, Cowell CT. Prevention and treatment of osteoporosis in chronically ill children. J Musculoskelet Neuronal Interact. 2005;5(3):262-72.

26. Kim SJ, Kim SN, Yang YN, Lee IS, Koh SE. Effect of weight bearing exercise to improve bone mineral density in children with cerebral palsy: a metaanalysis. J Musculoskelet Neuronal Interact. 2017;17(4):334-40.

27. Palomo T, Vilaca T, Lazaretti-Castro M. Osteogensesis imperfecta: diagnosis and treatment. Curr Opin Endocrinol Diabetes Obes. 2017;24(6):381-8. https://doi.org/10.1097/med.0000000000000367. 